\title{
A proof-of-concept study of growth hormone in children with Phelan-McDermid syndrome
}

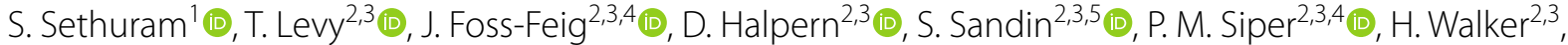 \\ J. D. Buxbaum $2,3,4,6,7$ D, R. Rapaport ${ }^{8}$ (D) and A. Kolevzon ${ }^{2,3,8^{*}}$ (D)
}

\begin{abstract}
Background: Phelan-McDermid syndrome (PMS) is caused by 22q13 deletions including SHANK3 or pathogenic sequence variants in SHANK3 and is among the more common rare genetic findings in autism spectrum disorder (ASD). SHANK3 is critical for synaptic function, and preclinical and clinical studies suggest that insulin-like growth factor-1 (IGF-1) can reverse a range of deficits in PMS. IGF-1 release is stimulated by growth hormone secretion from the anterior pituitary gland, and this study sought to assess the feasibility of increasing IGF-1 levels through recombinant human growth hormone $(\mathrm{rhGH})$ treatment, in addition to establishing safety and exploring efficacy of rhGH in children with PMS.
\end{abstract}

Methods: rhGH was administered once daily for 12 weeks to six children with PMS using an open-label design. IGF-1 levels, safety, and efficacy assessments were measured every 4 weeks throughout the study.

Results: rhGH administration increased levels of IGF-1 by at least 2 standard deviations and was well tolerated without serious adverse events. rhGH treatment was also associated with clinical improvement in social withdrawal, hyperactivity, and sensory symptoms.

Limitations: Results should be interpreted with caution given the small sample size and lack of a placebo control.

Conclusions: Overall, findings are promising and indicate the need for larger studies with rhGH in PMS.

Trial registration NCT04003207. Registered July 1, 2019, https:/clinicaltrials.gov/ct2/show/NCT04003207.

Keywords: Phelan-McDermid syndrome, PMS, Shank3, Autism spectrum disorder, ASD, Growth hormone, Insulin-like growth factor-1, IGF-1

\section{Introduction}

Phelan-McDermid syndrome (PMS) is caused by deletions in the long arm of chromosome 22 which include the SHANK3 gene (MIM: 606230), or by pathogenic sequence variants in SHANK3 [1-4]. PMS is associated

\footnotetext{
*Correspondence: alexander.kolevzon@mssm.edu

${ }^{2}$ Seaver Autism Center for Research and Treatment, Icahn School

of Medicine at Mount Sinai, One Gustave L. Levy Place, Box 1230, New York, NY 10029, USA

Full list of author information is available at the end of the article
}

with developmental delays, intellectual disability, and autism spectrum disorder (ASD), in addition to renal, cardiac, and gastrointestinal abnormalities, hypotonia, and dysmorphic features [5]. SHANK3 has been established as the critical gene in PMS [1-4, 6] and appears to account for $\sim 0.5 \%$ of ASD [7]. SHANK3 encodes for a master scaffolding protein in the post-synaptic density of excitatory synapses and is responsible for the formation and maintenance of synapses [8]. As such, SHANK3 and associated pathways represent important targets for intervention.

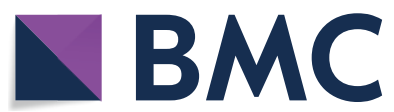

(c) The Author(s) 2022. Open Access This article is licensed under a Creative Commons Attribution 4.0 International License, which permits use, sharing, adaptation, distribution and reproduction in any medium or format, as long as you give appropriate credit to the original author(s) and the source, provide a link to the Creative Commons licence, and indicate if changes were made. The images or other third party material in this article are included in the article's Creative Commons licence, unless indicated otherwise in a credit line to the material. If material is not included in the article's Creative Commons licence and your intended use is not permitted by statutory regulation or exceeds the permitted use, you will need to obtain permission directly from the copyright holder. To view a copy of this licence, visit http://creativecommons.org/licenses/by/4.0/. The Creative Commons Public Domain Dedication waiver (http://creativeco mmons.org/publicdomain/zero/1.0/) applies to the data made available in this article, unless otherwise stated in a credit line to the data. 
Evidence from both preclinical and clinical studies suggests that insulin-like growth factor-1 (IGF-1) can reverse deficits in synaptic plasticity and motor learning in mouse and human neuronal models of PMS [9, 10]. A clinical trial with IGF-1 in children with PMS also showed improvement in social withdrawal and restricted behaviors, both core features of ASD [11]. Additional evidence of the utility of IGF-1 comes from animal, human, and human neuronal studies of Rett syndrome, another rare genetic disorder associated with ASD, where IGF-1 was effective in reversing phenotypic features [12-16].

IGF-1 is released mainly by the liver upon growth hormone stimulation and enters the brain from the circulation to promote brain vessel growth [17], neurogenesis, and synaptogenesis [18]. Once IGF-1 binds to the IGF-1 receptor, activation of the PI3K/mTOR/AKT1 and MAPK/ERK pathways induces its downstream effects [19]. Treatment with IGF-1 is generally administered twice daily via subcutaneous injection and requires careful monitoring due to numerous risks, including hypoglycemia. Further, IGF-1 is challenging to manufacture and while commercially approved for short stature due to primary IGF-1 deficiency, it is costly and not readily available. However, IGF-1 levels can be increased intrinsically by growth hormone [20] without the risk of hypoglycemia. Recombinant human growth hormone (rhGH) has an excellent safety profile and approved indications in pediatric and adult populations. One recent case report also supports the use of rhGH in PMS [21]. For these reasons, rhGH was chosen for this trial with the primary aims of demonstrating the feasibility of increasing IGF-1 levels in the blood and establishing safety in PMS. Furthermore, we sought to explore signals of efficacy using a battery of clinical outcome assessments, including the Aberrant Behavior Checklist-Social Withdrawal subscale $(\mathrm{ABC}-\mathrm{SW})$ [22] as the primary clinical outcome. The ABC-SW subscale was chosen based on results from the previous clinical trial with IGF-1 in PMS [11].

\section{Methods}

This study was approved by the Program for the Protection of Human Subjects at the Icahn School of Medicine at Mount Sinai, and all caregivers provided written informed consent.

\section{Inclusion/exclusion criteria}

Participants were required to have a confirmed genetic diagnosis of PMS and be between 2 and 12 years of age. Participants were excluded if they had closed epiphyses, active or suspected neoplasia, intracranial hypertension, hepatic insufficiency, renal insufficiency, cardiomegaly/ valvulopathy, or allergy to growth hormone or any component of the formulation.

\section{Drug administration}

rhGH was administered in its commercially available form as somatropin (Zomacton). Caregivers were trained by a pediatric endocrinologist (Sethuram, S) to administer rhGH subcutaneously, through demonstration and written material. rhGH was given once daily for 12 weeks using an open-label design. Doses were based on standard clinical practice for children who are not growth hormone deficient with a target dose of $0.3 \mathrm{mg} / \mathrm{kg} /$ week. All participants were initiated on half the target dose $(0.14-0.16 \mathrm{mg} / \mathrm{kg} /$ week $)$ for two weeks as a safety precaution and then increased to a full dose for the remaining 10 weeks. IGF-1 levels were measured every 4 weeks, and IGF-1 $Z$ scores were used to guide titration of rhGH dose using two standard deviations (SD) above the population mean as the target.

\section{Safety measures and laboratories}

Medical and psychiatric history was collected prior to the onset of the trial. Safety laboratories, physical examinations, and IGF-1 values were collected at the baseline visit and at each follow-up visit: weeks 4 , 8 , and 12. Adverse events were collected at every visit using the Systematic Longitudinal Adverse Events Scale (SLAES).

\section{Clinical measures}

The primary clinical outcome was the ABC-SW subscale (ABC-SW) [22]. Additional clinical outcome assessments were used to capture a range of ASDrelated symptoms, including the Repetitive Behavior

Table 2 Adverse events

\begin{tabular}{ll}
\hline Adverse event & $\begin{array}{l}\text { Number of } \\
\text { participants }\end{array}$ \\
\hline Increase in appetite & 3 \\
Gastroenteritis & 3 \\
Polyuria/nocturia & 3 \\
Crying spells & 3 \\
Runny nose/cough/sneezing & 3 \\
Decrease in appetite & 1 \\
Fever & 3 \\
Worsening repetitive behavior & 2 \\
Eye/ear infection & 2 \\
Diarrhea & 1 \\
Worsening hyperactivity & 2 \\
Sleep disturbance & 1 \\
Disruptive behavior & 1 \\
Bruising at injection site & 1 \\
Sweating of hands/feet & 1 \\
Limping/gait changes & 1 \\
\hline
\end{tabular}


Table $1 \mathrm{rhGH}$ dose in mg/kg/week and IGF-1 Z scores

\begin{tabular}{|c|c|c|c|c|c|c|}
\hline Participant & & Baseline & Week 2 & Week 4 & Week 8 & Week 12 \\
\hline \multirow[t]{2}{*}{1} & |GF-1 Z score & 0.8 & - & 2.6 & 4.8 & 2.2 \\
\hline & rhGH dose & 0.15 & 0.3 & 0.28 & $0.24^{\mathrm{a}}$ & - \\
\hline \multirow[t]{2}{*}{2} & IGF-1 Z score & 1.0 & - & 6.0 & 5.0 & 3.9 \\
\hline & rhGH dose & 0.15 & 0.28 & $0.24^{\mathrm{a}}$ & $0.16^{\mathrm{a}}$ & - \\
\hline \multirow[t]{2}{*}{3} & IGF-1 Z score & 1.1 & - & 2.8 & 4.7 & 1.7 \\
\hline & rhGH dose & 0.14 & 0.3 & 0.29 & $0.24^{a}$ & - \\
\hline \multirow[t]{2}{*}{4} & IGF-1 Z score & 0.9 & - & 4.5 & 1.8 & 2.9 \\
\hline & rhGH dose & 0.16 & 0.29 & $0.21^{\mathrm{a}}$ & $0.19^{\mathrm{b}}$ & - \\
\hline \multirow[t]{2}{*}{5} & IGF-1 Z score & 2.3 & - & 4.9 & 4.2 & 1.3 \\
\hline & rhGH dose & 0.14 & 0.27 & $0.22^{\mathrm{a}}$ & $0.13^{\mathrm{a}}$ & - \\
\hline \multirow[t]{2}{*}{6} & IGF-1 Z score & -1.2 & - & 1.1 & 1.3 & 0.9 \\
\hline & rhGH dose & 0.15 & 0.31 & 0.33 & 0.32 & - \\
\hline
\end{tabular}

${ }^{\text {a }}$ Dose reduced due to high IGF-1 levels

${ }^{b}$ Dose reduced due to crying spells

Scales-Revised (RBS-R) [23], the Sensory Profile (SP) [24], other ABC subscales (Table 2), and the Clinical Global Impression-Improvement scale (CGI-I) [25].

\section{Statistical analyses}

Nonparametric Wilcoxon signed-rank tests were used to evaluate differences in clinical outcomes between baseline and week 12. All tests of statistical hypotheses were done on the two-sided $5 \%$ level of significance. We

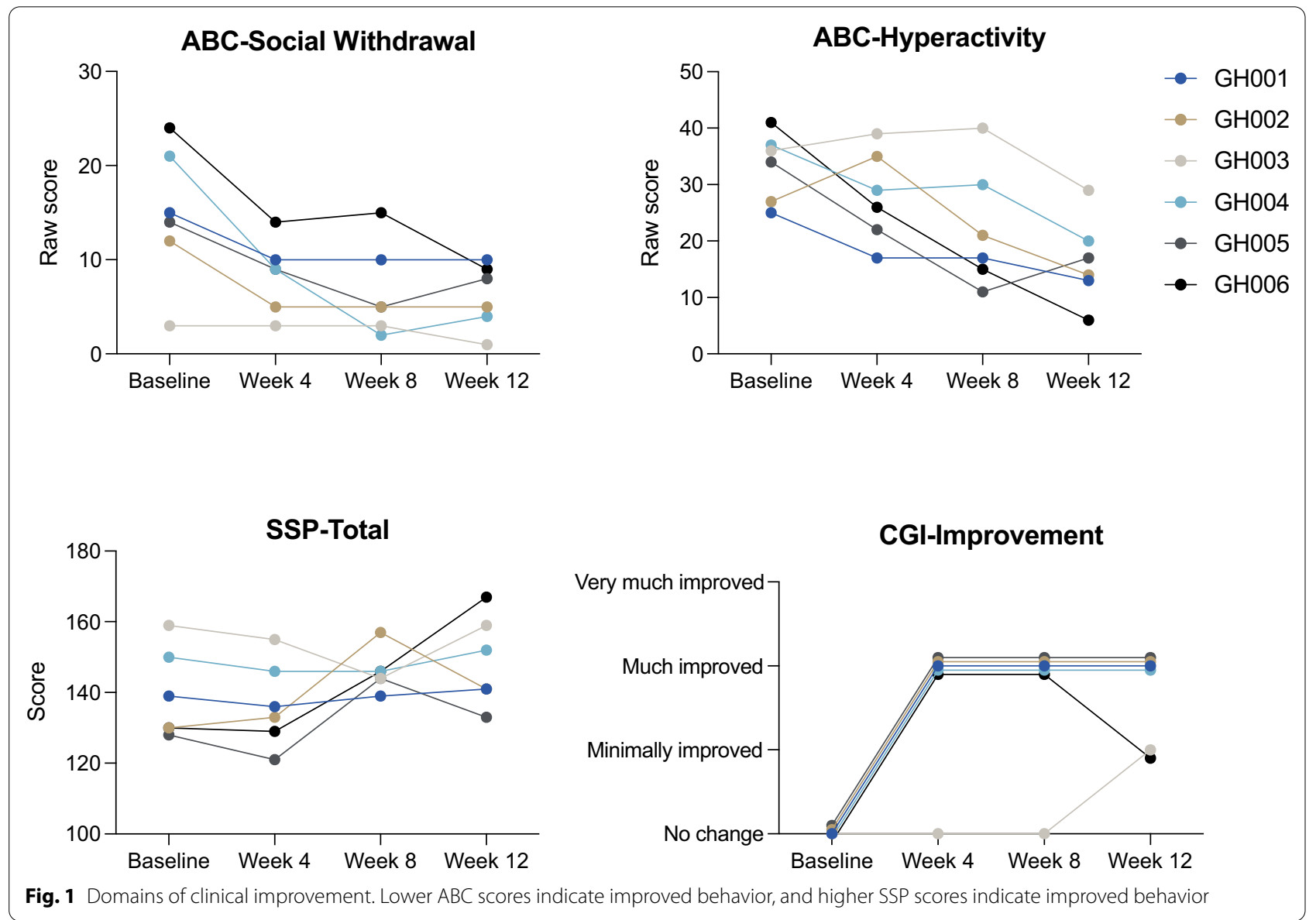


Table 3 Summary statistics for clinical outcomes

\begin{tabular}{|c|c|c|c|c|c|}
\hline Measure $^{a}$ & Variable & $\begin{array}{l}\text { Baseline } \\
\text { Mean (SD) }\end{array}$ & $\begin{array}{l}\text { Week } 12 \\
\text { Mean (SD) }\end{array}$ & $p$ value & $\begin{array}{l}\text { Wilcoxon } \\
r \text { effect }\end{array}$ \\
\hline \multirow[t]{5}{*}{$A B C$} & Irritability & $10.31(7.6)$ & $4.6(2.3)$ & 0.225 & 0.50 \\
\hline & Social withdrawal & $14.8(7.4)$ & $6.2(3.4)$ & 0.028 & 0.90 \\
\hline & Stereotypy & $8.8(6.9)$ & $5.1(1.8)$ & 0.249 & 0.47 \\
\hline & Hyperactivity & $33.3(6.2)$ & $16.5(7.7)$ & 0.027 & 0.90 \\
\hline & Inappropriate speech & $3.3(4.3)$ & $2.3(3.8)$ & 0.285 & 0.44 \\
\hline \multirow[t]{7}{*}{ RBS-R } & Stereotyped behavior & $4.3(1.7)$ & $4.0(2.4)$ & 0.577 & 0.23 \\
\hline & Self-injurious behavior & $0.7(0.8)$ & $1.3(1.8)$ & 0.157 & 0.58 \\
\hline & Compulsive behavior & $2.8(3.2)$ & $1.3(1.6)$ & 0.083 & 0.71 \\
\hline & Ritualistic behavior & $1.2(1.2)$ & $0.8(1.2)$ & 0.414 & 0.33 \\
\hline & Sameness behavior & $2.3(2.4)$ & $2.0(1.7)$ & 0.680 & 0.17 \\
\hline & Restricted behavior & $2.0(2.2)$ & $1.2(1.5)$ & 0.129 & 0.62 \\
\hline & Total & $13.3(6.1)$ & $10.7(3.1)$ & 0.248 & 0.47 \\
\hline \multirow[t]{8}{*}{ SSP } & Tactile & $31.5(2.1)$ & $31.7(2.0)$ & 1.00 & 0.00 \\
\hline & Taste/smell & $18.2(3.6)$ & $19.4(1.3)$ & 0.317 & 0.41 \\
\hline & Movement & $13.3(1.6)$ & $13.7(1.8)$ & 0.157 & 0.58 \\
\hline & Sensation & $17.5(4.8)$ & $20.0(2.4)$ & 0.416 & 0.33 \\
\hline & Auditory & $20.0(1.9)$ & $22.0(2.4)$ & 0.144 & 0.60 \\
\hline & Low energy/weak & $16.5(6.9)$ & $20.5(5.2)$ & 0.141 & 0.60 \\
\hline & Visual/auditory & $22.3(2.3)$ & $22.7(1.5)$ & 0.414 & 0.33 \\
\hline & Total & 139.3 & 148.8 & 0.042 & 0.83 \\
\hline CGI & Improvement score & - & $1.7(0.5)$ & 0.023 & 0.93 \\
\hline
\end{tabular}

ABC Aberrant Behavior Checklist, CGI Clinical Global Impressions scale, RBS-R Repetitive Behavior Scales-Revised, SSP Short Sensory Profile

${ }^{a}$ For the $A B C$ and RBS-R, lower scores indicate better performance; for the SSP and CGI-Improvement scale, higher scores indicate better performance

selected a single primary efficacy variable (ABC-SW) a priori and did not adjust for multiplicity of statistical tests. All raw $p$ values are presented to allow an adjustment post hoc (Table 3). In the case of missing data, we used the last observation carried forward. The sample size was not based on statistical criteria and was determined by feasiblity for this pilot study.

\section{Results}

\section{Participants}

This trial was conducted from September 2019 to June 2020 and terminated early due to COVID-19; the original recruitment target was 10 participants. Six participants were screened, and all met inclusion criteria and were enrolled. Participants ( 2 males; 4 females) were between 3.2 and 11.4 years of age $(7.5 \pm 3.2)$. All participants except one female were pre-pubertal. The one child who was pubertal on physical and biochemical evaluation did not reach menarche. At baseline, all children were of average weight $(-0.85 \pm 1.15 \mathrm{SD})$, height $(-1.38 \pm 0.75 \mathrm{SD})$, and body mass index $(-0.82 \pm 1.27)$. All bone ages were within the normal range. Baseline IGF-1 $Z$ scores varied between -1.2 and 2.3 (Table 1 ).

\section{Safety}

Recombinant human growth hormone was generally well tolerated, and there were no serious adverse events (Table 2). On average, participants experienced approximately five treatment emergent adverse events. One participant experienced gait changes, and rhGH was terminated early at week 11 out of an abundance of caution due to the risk of slipped capital femoral epiphysis. The participant was evaluated by their pediatrician, and no additional workup was deemed necessary; gait normalized within 2 days after stopping rhGH and without further sequelae. Another participant required dose reduction due to crying spells. Crying spells in all three participants were attributed to increased emotional lability. There were no clinically significant abnormalities on laboratory blood work.

\section{Efficacy}

There was an improvement in our primary clinical outcome, the ABC-SW subscale, between baseline and week $12(p=0.028)$ (Fig. 1). There was also an improvement in hyperactivity using the $\mathrm{ABC}$ hyperactivity subscale $(p=0.027)$, and in overall sensory symptoms as measured by the short sensory profile total score $(p=0.042)$. 
Overall, there was global improvement as measured by the CGI-I $(p=0.023)$. There were no significant changes in other clinical domains (Table 3).

\section{Discussion}

The results of this pilot open-label clinical trial demonstrate that standard clinical doses of rhGH increased levels of IGF-1 in children with PMS by at least 2SD from baseline for all participants; final levels of greater than or equal to 2SD were reached in all except one participant. Further, we show that rhGH was well tolerated without serious adverse events. As rhGH is already FDA-approved and established as safe in children with growth-related problems and in adults with growth hormone deficiency, these results provide preliminary evidence of safety in a new patient population without specific growth issues. rhGH treatment was also associated with clinical improvement that parallels the effects of IGF-1 on social withdrawal in this population. In addition, rhGH was associated with benefits in hyperactivity and sensory symptoms, all leading to global improvement based on the CGI-I. Studies of rhGH in PMS are ongoing using a randomized, placebo-controlled, crossover design. In addition, it will be critical to discover biomarkers to predict treatment response to rhGH in PMS, and potentially, within subgroups of ASD more broadly.

\section{Limitations}

Results should be interpreted with caution given the small sample size and open-label design of the study.

\section{Conclusions}

Taken together, these findings support the development of rhGH as treatment for children with PMS. Future studies of the effects of rhGH in PMS using an adequately powered placebo-controlled design are warranted.

\footnotetext{
Abbreviations

ABC: Aberrant Behavior Checklist; AEs: Adverse events; ASD: Autism spectrum disorder; CGI-I: Clinical Global Impression_Improvement Scale; IGF-1: Insulinlike growth factor-1; PMS: Phelan-McDermid syndrome; RBS-R: Repetitive Behavior Scale_-Revised; rhGH: Recombinant human growth hormone; SD: Standard deviation; SLAES: Systematic longitudinal adverse events scale; SSP: Short sensory profile.
}

\section{Acknowledgements}

The authors would like to thank the families who participated and the PhelanMcDermid Syndrome Foundation for their support in recruitment.

\section{Authors' contributions}

TL and S Sandin contributed to data analysis and manuscript writing; S Sethuram, DH, PS, RR, and AK contributed to study design, data collection, and manuscript writing; HW collected and entered data for analysis; JFF and JDB contributed to manuscript writing. All authors read and approved the final manuscript.

\section{Funding}

This study was supported in part by a grant from the Beatrice and Samuel A. Seaver Foundation and New York Community Trust.

\section{Availability of data and materials}

The datasets used and/or analyzed during the current study are available from the corresponding author on reasonable request.

\section{Declarations}

\section{Ethics approval and consent to participate}

The protocol was approved by the Mount Sinai Program for the Protection of Human Subjects, and all caregivers signed informed consent.

\section{Consent for publication}

Not applicable.

\section{Competing interests}

AK receives research support from AMO Pharma and consults to Acadia, Alkermes, Jaguar, Neuren, GW Pharma, and Ovid Therapeutics. JDB has a shared patent with Mount Sinai for IGF-1 in Phelan-McDermid syndrome. No other authors have competing interests to disclose.

\section{Author details}

${ }^{1}$ Department of Pediatrics, Saint Peter's University Hospital, New Brunswick, NJ, USA. ${ }^{2}$ Seaver Autism Center for Research and Treatment, Icahn School of Medicine at Mount Sinai, One Gustave L. Levy Place, Box 1230, New York, NY 10029, USA. ${ }^{3}$ Department of Psychiatry, Icahn School of Medicine at Mount Sinai, New York, NY, USA. ${ }^{4}$ Present Address: Mindich Child Health and Development Institute, Icahn School of Medicine at Mount Sinai, New York, NY 10029, USA. ${ }^{5}$ Department of Medical Epidemiology and Biostatistics, Karolinska Institutet, Stockholm, Sweden. ${ }^{6}$ Department of Neuroscience, Icahn School of Medicine at Mount Sinai, New York, NY, USA. ${ }^{7}$ Department of Genetics and Genomic Medicine, Icahn School of Medicine at Mount Sinai, New York, NY, USA. ${ }^{8}$ Department of Pediatrics, Icahn School of Medicine at Mount Sinai, New York, NY, USA.

Received: 22 September 2021 Accepted: 17 January 2022

Published online: 29 January 2022

\section{References}

1. Bonaglia MC, Giorda R, Borgatti R, Felisari G, Gagliardi C, Selicorni A, et al. Disruption of the ProSAP2 gene in a $(12 ; 22)(q 24.1 ; q 13.3)$ is associated with the 22q133 deletion syndrome. Am J Hum Genet. 2001;69(2):261-8.

2. Wilson HL, Wong AC, Shaw SR, Tse WY, Stapleton GA, Phelan MC, et al. Molecular characterisation of the 22q13 deletion syndrome supports the role of haploinsufficiency of SHANK3/PROSAP2 in the major neurological symptoms. J Med Genet. 2003;40(8):575-84.

3. Bonaglia MC, Giorda R, Mani E, Aceti G, Anderlid BM, Baroncini A, et al. Identification of a recurrent breakpoint within the SHANK3 gene in the 22q13.3 deletion syndrome. J Med Genet. 2006;43(10):822-8.

4. Durand CM, Betancur C, Boeckers TM, Bockmann J, Chaste P, Fauchereau $F$, et al. Mutations in the gene encoding the synaptic scaffolding protein SHANK3 are associated with autism spectrum disorders. Nat Genet. 2007:39(1):25-7.

5. Soorya L, Kolevzon A, Zweifach J, Lim T, Dobry Y, Schwartz L, et al. Prospective investigation of autism and genotype-phenotype correlations in 22q13 deletion syndrome and SHANK3 deficiency. Mol Autism. 2013:4(1):18

6. De Rubeis S, Siper PM, Durkin A, Weissman J, Muratet F, Halpern D, et al. Delineation of the genetic and clinical spectrum of Phelan-McDermid syndrome caused by SHANK3 point mutations. Mol Autism. 2018;9:31.

7. Betancur C, Buxbaum JD. SHANK3 haploinsufficiency: a "common" but underdiagnosed highly penetrant monogenic cause of autism spectrum disorders. Mol Autism. 2013;4(1):17.

8. Boeckers TM. The postsynaptic density. Cell Tissue Res. 2006;326(2):409-22. 
9. Bozdagi O, Tavassoli T, Buxbaum JD. Insulin-like growth factor-1 rescues synaptic and motor deficits in a mouse model of autism and developmental delay. Mol Autism. 2013;4(1):9.

10. Shcheglovitov A, Shcheglovitova O, Yazawa M, Portmann T, Shu R, Sebastiano $V$, et al. SHANK3 and IGF1 restore synaptic deficits in neurons from 22q13 deletion syndrome patients. Nature. 2013;503(7475):267-71.

11. Kolevzon A, Bush L, Wang AT, Halpern D, Frank Y, Grodberg D, et al. A pilot controlled trial of insulin-like growth factor-1 in children with PhelanMcDermid syndrome. Mol Autism. 2014;5(1):54.

12. Marchetto MC, Carromeu C, Acab A, Yu D, Yeo GW, Mu Y, et al. A model for neural development and treatment of Rett syndrome using human induced pluripotent stem cells. Cell. 2010;143(4):527-39.

13. Khwaja OS, Ho E, Barnes KV, O'Leary HM, Pereira LM, Finkelstein Y, et al. Safety, pharmacokinetics, and preliminary assessment of efficacy of mecasermin (recombinant human IGF-1) for the treatment of Rett syndrome. Proc Natl Acad Sci USA. 2014;111(12):4596-601.

14. Castro J, Garcia RI, Kwok S, Banerjee A, Petravicz J, Woodson J, et al. Functional recovery with recombinant human IGF1 treatment in a mouse model of Rett Syndrome. Proc Natl Acad Sci USA. 2014;111(27):9941-6.

15. Tropea D, Giacometti E, Wilson NR, Beard C, McCurry C, Fu DD, et al. Partial reversal of Rett syndrome-like symptoms in MeCP2 mutant mice. Proc Natl Acad Sci USA. 2009;106(6):2029-34.

16. Pini G, Congiu L, Benincasa A, DiMarco P, Bigoni S, Dyer AH, et al. Illness severity, social and cognitive ability, and EEG analysis of ten patients with Rett syndrome treated with mecasermin (recombinant human IGF-1). Autism Res Treat. 2016;2016:5073078.

17. Lopez-Lopez C, LeRoith D, Torres-Aleman I. Insulin-like growth factor I is required for vessel remodeling in the adult brain. Proc Natl Acad Sci USA. 2004;101 (26):9833-8.

18. O'Kusky JR, Ye P, D'Ercole AJ. Insulin-like growth factor-l promotes neurogenesis and synaptogenesis in the hippocampal dentate Gyrus during postnatal development. J Neurosci. 2000;20(22):8435-42.

19. Costales J, Kolevzon A. The therapeutic potential of insulin-like growth factor-1 in central nervous system disorders. Neurosci Biobehav Rev. 2016:63:207-22

20 Jorge AA, Grimberg A, Dattani MT, Baron J. Disorders of childhood growth. Sperling pediatric endocrinology. Elsevier; 2021. p. 299-356.

21. Xie RJ, LiTX, Sun C, Cheng C, Zhao J, Xu H, et al. Correction to: a case report of Phelan-McDermid syndrome: preliminary results of the treatment with growth hormone therapy. Ital J Pediatr. 2021;47(1):89.

22 Aman MG, Singh NN, Stewart AW, Field CJ. Psychometric characteristics of the aberrant behavior checklist. Am J Ment Defic. 1985;89:492-502.

23. Lam KS, Aman MG. The repetitive behavior scale-revised: independent validation in individuals with autism spectrum disorders. J Autism Dev Disord. 2007;37(5):855-66

24 Dunn W. Sensory profile. Psychological Corporation; 1999.

25. Guy W, ECDEU Assessment Manual for PR, Rockville M. US Department of Health, Education, and Welfare, Public Health Service, Alcohol, Drug Abuse, and Mental Health Administration, NIMH Psychopharmacology Research Branch, Division of Extramural Research Programs. 1976.

\section{Publisher's Note}

Springer Nature remains neutral with regard to jurisdictional claims in published maps and institutional affiliations.

Ready to submit your research? Choose BMC and benefit from:

- fast, convenient online submission

- thorough peer review by experienced researchers in your field

- rapid publication on acceptance

- support for research data, including large and complex data types

- gold Open Access which fosters wider collaboration and increased citations

- maximum visibility for your research: over $100 \mathrm{M}$ website views per year

At BMC, research is always in progress.

Learn more biomedcentral.com/submissions 